\title{
Clinical guideline: antiepileptic drugs of choice for epileptic syndromes and epilepsies in pediatric patients
}

\author{
Juan C. Reséndiz-Aparicio ${ }^{1}$, Jesús M. Padilla-Huicab², Iris E. Martínez-Juárez³, \\ Gustavo Hernández-Martínez ${ }^{4}$, Eunice López-Correa ${ }^{5}$, Benjamín Vázquez-Juárez ${ }^{6}$, \\ Rosana Huerta-Albarrán ${ }^{7}$ and Claudia Rivera-Acuña ${ }^{8}$
}

${ }^{1}$ PPE, Instituto Nacional de Neurología y Neurocirugía Dr. Manuel Velasco Suárez y Hospital Psiquiátrico Infantil Dr. Juan N. Navarro, Mexico City; ${ }^{2}$ Hospital General de Especialidades Dr. Javier Buenfil Osorio, Campeche; 3 Instituto Nacional de Neurología y Neurocirugía Dr. Manuel Velasco Suárez Mexico City; ${ }^{4}$ Centro de Alta Especialidad del Estado de Veracruz Dr. Rafael Lucio, Jalapa, Veracruz; ${ }^{5}$ Hospital General Dr. Gaudencio González Garza, Centro Médico La Raza, IMSS, Mexico City; ${ }^{6}$ Hospital para el Niño Poblano, Puebla; ${ }^{7}$ Hospital General de México Dr Eduardo Liceaga, Mexico City; ${ }^{8}$ Hospital Regional de Alta Especialidad ISSSTE, Puebla. México

\begin{abstract}
Approximately $65 \%$ of children with newly diagnosed epilepsy achieve sustained control of their epileptic seizures with the antiepileptic drug (AED) initially prescribed, and 15-20\% require the combination of other AEDs. To begin treatment with an $A E D$, basic aspects should be considered, such as the capacity for absorption, distribution, metabolism, and elimination of each AED. Treatment with an AED in pediatric patients, as for any age, must be personalized, but in these cases, the biological age and its degree of development are fundamental. Furthermore, the type of seizure, type of epileptic syndrome, comorbidity, in many cases the etiology, and even other aspects such as tolerability and availability of use must be considered. If adequate seizure control is not achieved, synergistic combinations could be used, making sure that adverse effects are not increased. Remember that a high percentage of patients initiate their epilepsy in the pediatric stage, which is why management in this age group is fundamental, and doses must always be calculated in relation to the weight of the patient.
\end{abstract}

Key words: Antiepileptic drug. Monotherapy. Polytherapy. Childhood. Pediatric.

\section{Introduction}

This is a clinical guide for the pharmacologic treatment of epilepsy in pediatric patients. It consists of establishing PICO-based questions and setting forth answers. The levels of evidence are based on articles published in peer-reviewed indexed articles and other international guidelines, such as the guides published by the International League Against Epilepsy, the National Institute for Health Care Excellence, and the Guidelines from the Sociedad Andaluza de Epilepsia (Andalusian Epilepsy Society). In addition, we emit recommendations from the Programa Prioritario de Epilepsia (Priority Epilepsy Program).

\section{Correspondence:}

Juan Carlos Reséndiz Aparicio

E-mail: jc_doc@yahoo.com
Available online: 12-04-2019 Rev Mex Neuroci. 2019;20(2):89-96 www.revmexneurociencia.com 1665-5044/C 2019. Academia Mexicana de Neurología A.C. Published by Permanyer México. This is an Open Access article under the CC BY-NC-ND license (http://creativecommons.org/licenses/by-nc-nd/4.0/). 


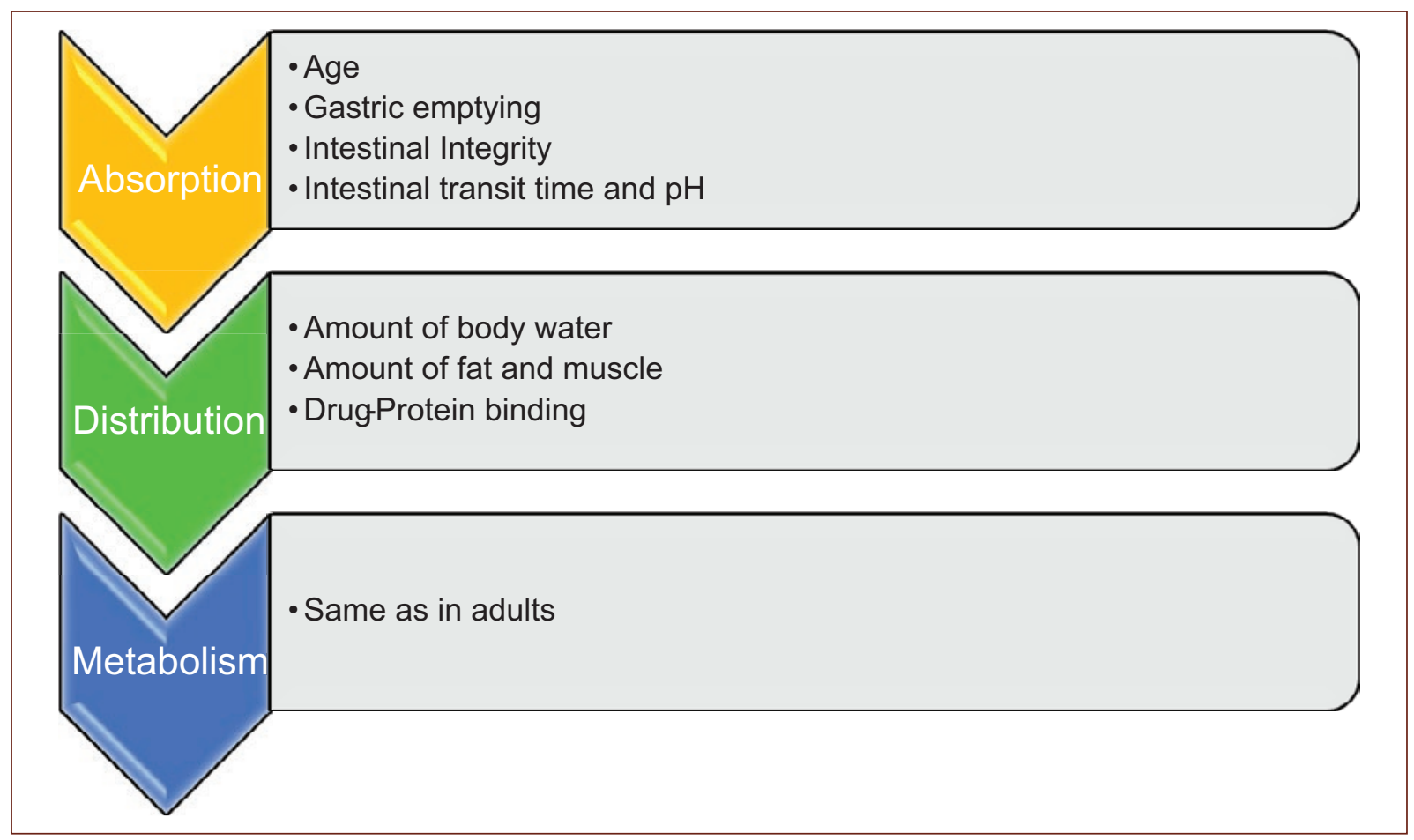

Figure 1. Pharmacokinetic and pharmacodynamic variables in pediatric age and use of antiepileptic drugs ${ }^{1-6}$.

Question 1. What are the pharmacokinetic and pharmacodynamic differences in pharmacologic management of epilepsy between the pediatric patient and the adult?

Pediatric patients have a broad range of variations in their ability for absorption, distribution, metabolism, and clearance of antiepileptic drugs (AEDs) (Fig. 1). Clearance of $A E D$ is much faster than in adults, which makes it important to calculate the dose depending on the weight or body surface area and to be careful of the toxic effects (Tables 1 and 2) $)^{1-6}$.

\section{Question 2. Should treatment with} antiepileptics be based on the type of epileptic syndrome that a patient presents?

To establish a diagnosis of epilepsy, it is sufficient if we can define an epileptic síndrome ${ }^{7}$ that, in the current classification, would correspond to a Level III diagnosis $^{8}$. By definition, an epileptic syndrome presupposes a disease that incorporates characteristics in common such as the type of seizure, the electroencephalographic findings, the shared imaging study results, age of onset and/or remission, when applicable, seizure triggering factors, diurnal variations, and sometimes the prognosis $^{8}$.

\section{Question 3. What is the evidence for treating epileptic syndromes described for newborns: benign familial neonatal epilepsy (BFNE), early myoclonic encephalopathy (EME), and Ohtahara syndrome?}

The first thing to understand is that neither systematic reviews nor clinical guides exist for the management of the syndromes that have been described in newborns; thus, the evidence for treatment is Level IV, and in all these cases, the recommendation is $U$.

\section{BFNE}

For cases with frequent seizures or status epilepticus, it could be necessary to provide therapy with drugs such as carbamazepine (CBZ), phenytoin (PHT), phenobarbital (PB), levetiracetam (LEV), oxcarbazepine (OXC), and valproate (VPA). CBZ, even at low doses, is considered to be a good option for BFNE, even in status epilepticus ${ }^{9,10}$. In general, patients require treatment during the first 6-12 months of life. 
Table 1. Traditional antiepileptic drugs and their pediatric use

\begin{tabular}{|c|c|c|c|c|}
\hline AED & Initial dose (mg/kg/day) & Maintenance dose & Daily dose & Presentation \\
\hline Diazepam & $\begin{array}{l}2-5 \text { years: } 1.5 \\
6-11 \text { years: } 0.9\end{array}$ & $\begin{array}{l}\text { Same } \\
\text { Same }\end{array}$ & 3 times & $\begin{array}{l}\text { Solution: } 5 \mathrm{mg} / 5 \mathrm{ml} \\
\text { Tablets: } 10 \mathrm{mg}\end{array}$ \\
\hline Carbamazepine & $5-10$ & $15-20 \mathrm{mg} / \mathrm{kg} / \mathrm{day}$ & 2 or 3 times & $\begin{array}{l}\text { Suspension: } 100 \mathrm{mg} / 5 \mathrm{ml} \\
\text { Tablets: } 200 \mathrm{mg}\end{array}$ \\
\hline Clobazam & 0.25 & $1 \mathrm{mg} / \mathrm{kg} / \mathrm{day}$ & Once or twice & Tablets: $10 \mathrm{mg}$ \\
\hline Clonazepam & 0.01 & $0.1 \mathrm{mg} / \mathrm{kg} / \mathrm{day}$ & 2 or 3 times & $\begin{array}{l}\text { Suspension: } 0.1 \mathrm{mg} / 1 \mathrm{ml} \\
\text { Tablets: } 2 \mathrm{mg}\end{array}$ \\
\hline Phenytoin & $4-5$ & 4-8 mg/kg/day & 2 or 3 times & $\begin{array}{l}\text { Suspension: } 37.5 \mathrm{mg} / 5 \mathrm{ml} \\
\text { Tablets: } 100 \mathrm{mg}\end{array}$ \\
\hline Phenobarbital & 5 & Same & Once or twice & Tablets: $100 \mathrm{mg}$ \\
\hline Gabapentin & $10-15$ & $30-100 \mathrm{mg} / \mathrm{kg} / \mathrm{day}$ & 2 or 3 times & Capsules: 300 and $400 \mathrm{mg}$ \\
\hline Lamotrigine & 0.5 & $2-10 \mathrm{mg} / \mathrm{kg} /$ day & Twice & Tablets: 25,50 , and $100 \mathrm{mg}$ \\
\hline Levetiracetam & 10 & $40-60 \mathrm{mg} /$ day & Twice & $\begin{array}{l}\text { Solution: } 100 \mathrm{mg} / \mathrm{ml} \\
\text { Tablets: } 250,500 \text {, and } 1000 \mathrm{mg} \\
500 \mathrm{mg} \text { extended release }\end{array}$ \\
\hline Oxcarbazepine & $5-10$ & $20-30 \mathrm{mg} / \mathrm{kg} / \mathrm{day}$ & Once or twice & $\begin{array}{l}\text { Suspension: } 300 \mathrm{mg} / 5 \mathrm{ml} \\
\text { Tablets: } 300 \text { and } 600 \mathrm{mg} \\
150,300 \text {, and } 600 \mathrm{mg} \text { extended release }\end{array}$ \\
\hline Pregabalin & $3.5-5$ & $15-20 \mathrm{mg} / \mathrm{kg} / \mathrm{day}$ & Twice & Capsules: 75 and $150 \mathrm{mg}$ \\
\hline Topiramate & $0.5-1.0$ & $4-8 \mathrm{mg} / \mathrm{kg} / \mathrm{day}$ & Twice & Tablets: 25,50 , and $100 \mathrm{mg}$ \\
\hline Valproic acid & $10-15$ & $15-30 \mathrm{mg} / \mathrm{kg} /$ day & 2 or 3 times & $\begin{array}{l}\text { Syrup: } 250 \mathrm{mg} / 5 \mathrm{ml} \\
\text { Sprinkle: } 125 \mathrm{mg} \\
\text { Capsules: } 250 \mathrm{mg} \text { and } 500 \mathrm{mg} \\
250 \mathrm{mg} \text { and } 500 \mathrm{mg} \text { extended release }\end{array}$ \\
\hline Vigabatrin & 40 & $\begin{array}{c}80-100 \mathrm{mg} / \mathrm{kg} / \mathrm{day} \\
\text { (150 mg/kg/per day for } \\
\text { childhood spasms) }\end{array}$ & 2 or 3 times & Tablets: $500 \mathrm{mg}$ \\
\hline
\end{tabular}

Table 2. New antiepileptic drugs and their use in pediatric age patients

\begin{tabular}{|c|c|c|c|c|c|}
\hline Drug & $\begin{array}{l}\text { Initial dose } \\
\text { (mg, } \mathrm{kg} \text {, day) }\end{array}$ & Maintenance & Daily dose & Secondary effects & Formulation \\
\hline Lacosamide & $1-2$ & $6-9$ & 2 & $\begin{array}{l}\text { Dizziness, cephalea, } \\
\text { double vision, nausea }\end{array}$ & Tablets: 50 and $100 \mathrm{mg}$ \\
\hline $\begin{array}{l}\text { Lamotrigine/monotherapy } \\
\text { With enzyme inducing AED } \\
\text { With Valproate }\end{array}$ & $\begin{array}{c}0.5 \\
2 \\
0.2\end{array}$ & $\begin{array}{c}2-10 \\
5-15 \\
1-5\end{array}$ & $\begin{array}{c}2 \\
2 \\
1-2\end{array}$ & $\begin{array}{l}\text { Skin rash, drowsiness, } \\
\text { dizziness, nausea, } \\
\text { double vision }\end{array}$ & $\begin{array}{l}\text { Tablets: } 5,25,50 \text {, and } \\
100 \mathrm{mg}\end{array}$ \\
\hline Levetiracetam & 10 & $20-60$ & 2 & $\begin{array}{l}\text { Cephalea, anorexia, } \\
\text { drowsiness, behavior } \\
\text { problems }\end{array}$ & $\begin{array}{l}\text { Tablets: } 250,500 \text {, and } \\
1000 \mathrm{mg} \\
\text { Suspension: } 100 \mathrm{mg} / 1 \mathrm{ml}\end{array}$ \\
\hline Oxcarbazepine & $5-8$ & $10-30$ & 2 & $\begin{array}{l}\text { Dizziness, ataxia, } \\
\text { drowsiness, } \\
\text { hyponatremia }\end{array}$ & $\begin{array}{l}\text { Tablets: } 300 \text { and } 600 \mathrm{mg} \\
\text { Suspension: } 300 \mathrm{mg} / 5 \mathrm{ml}\end{array}$ \\
\hline Topiramate & 1 & $6-9$ & 2 & $\begin{array}{l}\text { Weight loss, lethargy, } \\
\text { anorexia, hyperthermia, } \\
\text { kidney stones }\end{array}$ & Tablets: 25,50 , and $100 \mathrm{mg}$ \\
\hline Vigabatrin & $20-50$ & $50-150$ & 2 & $\begin{array}{l}\text { Hyperkinesis, weight } \\
\text { gain, insomnia, visual } \\
\text { field defects }\end{array}$ & Tablets: $500 \mathrm{mg}$ \\
\hline
\end{tabular}


Table 3. Treatment for West syndrome*

\begin{tabular}{l|l|l|}
\hline $\begin{array}{l}\text { Insufficient data to determine whether ketogenic diet, immunoglobulin, LEV, NZP, TPM, VPA, or } \\
\text { vitamin B6 are effective for treating infantile spasms }\end{array}$ & Evidence & Recommendation \\
\hline $\begin{array}{l}\text { Using rapid ACTH or prednisolone in unknown cause West syndrome improves long-term } \\
\text { cognitive results }\end{array}$ & U II and III & C \\
\hline $\begin{array}{l}\text { Insufficient studies to establish what other forms of corticosteroids are as effective and } \\
\text { recommended as ACTH to treat short-term infantile spasms }\end{array}$ & III and IV & U \\
\hline $\begin{array}{l}\text { Low-dose ACTH (20-30 UI) versus high dose (150 UI/m²) shows similar efficacy } \\
\text { ACTH is more effective than VGB for infantile spasms not associated with tuberous sclerosis }\end{array}$ & I and II & B \\
\hline VGB is more effective for infantile spasms associated with tuberous sclerosis & C \\
\hline $\begin{array}{l}\text { First-line drugs are ACTH, steroids, or VGB and second-line drugs are BZD, ketogenic diet, } \\
\text { TPM, and VPA }\end{array}$ & IV & C \\
\hline
\end{tabular}

*The AEDs are in alphabetical order and are available in Mexico ${ }^{12,13}$, LEV: levetiracetam, NZP: nitrazepam, TPM: topiramate, VPA: valproate, VGB: vigabatrin, BZD: benzodiazepines.

\section{EME}

Early onset with a burst suppression pattern in the EEG, various types of seizures, and psychomotor retardation. Metabolic etiologies are often a cause of EME. The burst suppression pattern in EME is different from that of Ohtahara since, in general, the burst is shorter and the suppression is longer. The use of steroids and ACTH may be effective in some cases ${ }^{11}$.

\section{Ohtahara syndrome}

It has been calculated that $75 \%$ of these cases evolve into West syndrome between the $2^{\text {nd }}$ and $6^{\text {th }}$ months of age. Treatment is difficult, but in some cases, ACTH, LEV, and high doses of PB have been shown to be effective ${ }^{11}$.

\section{Question 4. What is the evidence for treating West syndrome?}

There are insufficient data to determine the effectiveness of ketogenic diet, intravenous immunoglobulin, LEV, nitrazepam, topiramate (TPM), VPA, or Vitamin B6, for treating infantile spasms ${ }^{12}$.

Early control of spasms could improve development in those who do not have a proven underlying etiology ${ }^{13}$. For West of unknown cause, providing treatment quickly with ACTH or prednisolone, above using vigabatrin (VGB), can improve cognitive results in the long term ${ }^{12}$. Both steroids and VGB have potentially serious secondary effects, and the patient must be carefully observed.
The current studies are not enough to establish whether other types of corticosteroids, such as prednisolone, dexamethasone, or methylprednisolone, may be as effective or recommendable as ACTH for short-term treatment of infantile spasms ${ }^{12}$.

First-line treatment medications are considered to be ACTH, steroids, or VGB, while second-line treatment can be benzodiazepines, ketogenic diet, TPM, and VPA, although the long-term benefits of the different therapies are still uncertain, and more research is needed on this subject (Table 3$)^{13}$.

\section{Question 5. What is the evidence for treating Lennox-Gastaut syndrome?}

To choose the treatment, one must consider the behavioral and psychiatric comorbidities, such as depression, anxiety, and psychosis. One must also take into account that the patient may have different types of seizures and some drugs may diminish some types of seizures while increasing others. Some combinations can be synergistic and reduce the number of seizures, but it is important to monitor the possible increase in adverse effects (Table 4) 44,15 .

Valproate is a first-line drug, while CLB, ketogenic diet, lamotrigine (LTG), LEV, and TPM are effective as adjunct (add-on) therapies ${ }^{15-19}$. Other options for resistant seizures are cannabidiol, resective surgery, stimulation of the vagus nerve, callosotomy, or transcranial stimulation ${ }^{20-22}$. 
Table 4. Treatment for Lennox-Gastaut Syndrome

\begin{tabular}{|l|l|l|}
\hline VPA is the first-line drug for LGS & Level evidence & Recommendation \\
\hline CLB, LTG, LEV, and TPM are effective as adjunct therapy & II and III & B \\
\hline Ketogenic diet is recommended for drug-resistant seizures in LGS & II and III & B \\
\hline Cannabidiol is useful for resistant seizures in LGS & III & A \\
\hline Callosotomy is useful for atonic seizures in LGS & I and III & C \\
\hline Vagus nerve stimulation is useful for drug-resistant seizures in LGS & III & C \\
\hline The use of CBZ, GBP, OXC, PGB, or VGB is not recommended in LGS & III & IV \\
\hline
\end{tabular}

*The AED are in alphabetical order and are available in Mexico ${ }^{15-22}$. VPA: valproate, CLB: clobazam, LTG: lamotrigine, LEV: levetiracetam, TPM: topiramate, CBZ: carbamazepine, GBP: gabapentin, OXC: oxcarbazepine, PGB: pregabalin, VGB: vigabatrin

Table 5. Treatment in Doose syndrome $23-25$

\begin{tabular}{|l|l|l|}
\hline & Evidence & Recommendation \\
\hline LTG & II & B \\
\hline VPA & IV & R-PPE \\
\hline Ketogenic diet & IV & U \\
\hline
\end{tabular}

LTG: Lamotrigine, VPA: valproate

\section{Question 6. What drugs are the most effective for pediatric patients with myoclonic astatic epilepsy or Doose syndrome?}

VPA is considered the first choice AED, and it can be combined with BZD, ethosuximide (ESM), LTG, LEV, and $\mathrm{TPM}^{23}$.

The ketogenic diet can be very effective. The anti-epileptics that should be avoided are CBZ, gabapentin (GBP), OXC, pregabalin (PGB), tiagabine, and VGB since these increase myoclonic epileptic seizures (ES) $(\text { Table 5) })^{24,25}$.

\section{Question 7. What pharmacological treatment is recommended for pediatric patients with Dravet syndrome?}

ESs in these patients are refractory. A good combination is VPA with TPM, which has shown improvement, especially for focal seizures and generalized tonic-clonic ES. In some cases, ACTH or corticoids, ketogenic diet, ESM, or intravenous immunoglobulin has shown satisfactory results ${ }^{26}$. CBZ, GBP, LTG, OXC,
PHT, PGB, and VGB should not be used, as they can aggravate myoclonic ES (Table 6) ${ }^{15}$.

\section{Question 8. What drugs should be used for early onset occipital epilepsy or Panayiotopoulos syndrome?}

Evidence places $O X C$ at Level $A$, while $C B Z, P B$, PHT, TPM, VPA, and VGB are Level C, and CLB, CZP, and LTG are potentially Level $D$, with respect to efficacy/effectiveness, as initial monotherapy in children with focal onset epilepsy that have been recently diagnosed or without previous therapy ${ }^{27}$.

\section{Question 9. What drug must be used for juvenile myoclonic epilepsy?}

TPM and VPA are potentially effective (Level D) for any type of seizure within this syndrome. Avoid administering CBZ, GBP, OXC, PHT and VGB, since they can aggravate or trigger absence seizures, myoclonus, and in some cases, generalized tonic-clonic seizures. Furthermore, LTG may exacerbate myoclonic seizures in some cases (Level F) 28,29 .

\section{Question 10. What is the evidence for treating generalized epilepsy with generalized tonic-clonic ES in pediatric patients?}

There are no Class I or II studies on pediatric-aged patients, leaving us with only class III studies, and thus, Level $C$ evidence that suggests that monotherapy with CLB, LTG, LEV, TPM and VPA may be effective ${ }^{30-33}$. 
Table 6. Treatment in Dravet syndrome*

\begin{tabular}{|l|l|l|}
\hline & Level evidence & Recommendation \\
\hline VPA is effective for myoclonic seizures & IV & R-PPE \\
\hline $\begin{array}{l}\text { LTG may worsen or trigger myoclonic ES in patients with Juvenile myoclonic } \\
\text { epilepsy or Dravet syndrome }\end{array}$ & IV & R-PPE \\
\hline CLB, CNZ, LTG, LEV, and TPM are also effective for myoclonic seizures & IV & U \\
\hline
\end{tabular}

*The AED are in alphabetical order and are available in Mexico ${ }^{15,26}$, VPA: valproate, LTG: lamotrigine, CLB: clobazam, CNZ: clonazepam, LEV: levetiracetam, TPM: topiramate, ES: Epileptic seizures

Table 7. Treatment in epilepsy for generalized tonic-clonic epileptic seizures only in pediatric age patients*

\begin{tabular}{|l|l|l|}
\hline $\begin{array}{l}\text { Initial CLB monotherapy may be slightly more effective in treating epilepsy } \\
\text { with GTCS than PHT. No advantage over CBZ }\end{array}$ & II & Recommendation \\
\hline $\begin{array}{l}\text { CBZ and LTG may be effective as monotherapy for epilepsy with GTCS. } \\
\text { There is greater treatment failure with CBZ but quicker response in } \\
\text { controlling seizures (6 months) }\end{array}$ & II & B \\
\hline $\begin{array}{l}\text { CBZ and PHT can be effective as monotherapy for treating epilepsy with } \\
\text { GTCS, no difference between them when comparing effectiveness and } \\
\text { adverse effects }\end{array}$ & II & B \\
\hline LEV, TPM, and VPA can be effective in treating epilepsy with GTCS & III & R-PPE \\
\hline
\end{tabular}

*The AED are in alphabetical order and are available in Mexico ${ }^{29-33}$, CLB: Clobazam, PHT: phenytoin, CBZ: carbamazepine, LTG: lamotrigine, LEV: levetiracetam, TPM: topiramate, VPA: valproate

Table 8. Meta-analysis from the Cochrane library among first-generation AEDs for the treatment of focal ES*

\begin{tabular}{|l|l|}
\hline Study & Conclusions \\
\hline Tudur 2002 & CBZ and PHT show similar effectiveness in treating focal ES \\
\hline $\begin{array}{l}\text { Tudur 2003 } \\
\text { Tudur 2007 }\end{array}$ & PB is less tolerated than CBZ (with similar effectiveness) \\
\hline Nolan 2013 & PB is less tolerated than PHT (with similar effectiveness) \\
\hline Nolan 2013 & PHT and VPA present similar effectiveness to control ES \\
\hline Glauser 2006 & $\begin{array}{l}\text { CBZ and PHT show efficacy and effectiveness with good quality evidence } \\
\text { VPA show efficacy and effectiveness with low-quality evidence }\end{array}$ \\
\hline
\end{tabular}

*The AEDs are in alphabetical order and are available in Mexico ${ }^{28,37,42-44,} \mathrm{CBZ}$ : carbamazepine, PHT: phenytoin, ES: epileptic seizures, PB: phenobarbital VPA: valproate

CBZ and PHT must be avoided since they can aggravate or trigger GTCS (Table 7) ${ }^{29}$.

\section{Question 11. Which AED is considered to be first choice for recently diagnosed focal epilepsy in the pediatric patient?}

Around $65 \%$ of children with recently diagnosed epilepsy achieve sustained control of their ES with the
AED prescribed initially. An additional $15-20 \%$ of these patients require combination with other AEDs to achieve control. The remaining percentage does not achieve control with the available medicines, becoming a drug-resistant focal epilepsy ${ }^{34,35}$.

For childhood focal seizures, first-line monotherapy with GBP, LCM, LEV, LTG, OXC, PGB, and TPM is recommended. Alternative monotherapy includes $\mathrm{CBZ}$ or VPA, and as coadjuvant therapy CLB or LCM or one 
Table 9. Comparative studies between traditional and new AEDs in treating focal ES*

\begin{tabular}{|c|c|}
\hline Study & Conclusions \\
\hline Glauser 2006 & $\begin{array}{l}\text { Second-generation AEDs (GBP, LTG, OXC, and TPM) are not inferior in effectiveness compared with first-generation AEDs } \\
\text { Second-generation AEDs (GBP, LTG, OXC, and TPM) show similar efficacy }\end{array}$ \\
\hline Privitera 2003 & TPM (doses 100 or $200 \mathrm{mg} /$ day), CBZ (600 mg/day), and VPA (1250 mg/day) show similar efficacy results \\
\hline Gamble 2006 & LTG has better tolerability and adherence to treatment than CBZ \\
\hline $\begin{array}{l}\text { Nolan } 2013 \\
\text { Arya } 2013\end{array}$ & OXC shows similar efficacy compared to PHT, but it is tolerated better \\
\hline Koch 2009 & OXC presents similar efficacy and effectiveness compared with CBZ \\
\hline $\begin{array}{l}\text { Marson } 2007 \\
\text { Tudur } 2007\end{array}$ & $\begin{array}{l}\text { LTG shows greater effectiveness over CBZ, GBP, and TPM but not over OXC } \\
\text { CBZ demonstrates greater efficacy in seizure remission during } 12 \text { months compared to GBP but not greater than that } \\
\text { observed with LTG, OXC, and TPM } \\
\text { The AED with the lowest efficacy is GBP and the least tolerated is TPM } \\
\text { CBZ, LTG, and OXC show better adherence and better control during treatment of focal ES } \\
\text { VPA shows similar adherence as CBZ but with lower efficacy } \\
\text { PHT and TPM are less effective than LTG and have lower efficacy than CBZ }\end{array}$ \\
\hline $\begin{array}{l}\text { Brodie } 2007 \\
\text { Perry } 2008\end{array}$ & LEV demonstrates similar efficacy and tolerability CBZ for recently diagnosed focal epilepsy \\
\hline $\begin{array}{l}\text { CSGCE } 1998 \\
\text { Bawden } 1999\end{array}$ & $\begin{array}{l}\text { CLB shows similar efficacy as PHT and CBZ as monotherapy for the control of focal ES and GTCS } \\
\text { There are no differences in the results of cognitive tests applied to children at } 12 \text { months of treatment receiving CBZ } \\
\text { or CLB }\end{array}$ \\
\hline Rosenow 2012 & $\begin{array}{l}\text { There are no differences in efficacy or tolerability with LEV or LTG for control of focal ES or GS as monotherapy at } \\
26 \text { weeks of treatment in patients older than } 12 \text { years }\end{array}$ \\
\hline
\end{tabular}

*The AEDs are in alphabetical order and are available in Mexico ${ }^{28,37,42-52}$, AEDs: antiepileptic drugs, CBZ: carbamazepine, PHT: phenytoin, 0XC: oxcarbazepine, VPA: valproate, GBP: gabapentin, LTG: lamotrigine, LEV: levetiracetam, TPM: topiramate, CLB: clobazam

Table 10. Treatment for epilepsy with focal ES in pediatric age patients*

\begin{tabular}{|l|l|}
\hline $\begin{array}{l}\text { CBZ, GBP, LTG, OXC, PB, PHT, TPM, and VPA can be used as monotherapy for the initial } \\
\text { treatment of focal onset ES in children }\end{array}$ & Level of recommendation \\
\hline LEV can be used as monotherapy for initial treatment of focal onset ES in children & C \\
\hline
\end{tabular}

*The AEDs are in alphabetical order and are available in Mexico $28,37,42-52$, GBP: gabapentin, LTG: lamotrigine, LEV: levetiracetam, TPM: topiramate, VPA: valproate, OXC: oxcarbazepine, PB: phenobarbital, PHT: phenytoin

of the AEDs used as monotherapy can be used. When using VPA, remember the teratogenic risks for fertile-aged patients, especially when used in high doses (Tables 8-10) 28,36-44.

\section{Question 12. Which AEDs are considered to be the first choice for recently diagnosed generalized epilepsy in the pediatric patient?}

Choosing an AED for generalized seizures must be personalized according to age, type of seizure, tolerability, availability for use, and other aspects.
VPA continues to be the drug of choice as monotherapy for all types of generalized ES in children, after assessing the risk-benefit and taking into special consideration patients with cognitive deficits, risk of overweight, and teratogenic effects in fertile-aged adolescents. Other options include LEV and TPM. Administration of CBZ, GBP, LTG, OXC, PHT, and VGB should be avoided since they could precipitate generalized tonic-clonic seizures and myoclonic seizures ${ }^{15,29,35}$.

\section{Acknowledgments}

We thank Dr. Mitzel del Carmen Pérez-Careta for editorial assistance in preparing this Guide. 


\section{References}

1. Donovan MD, Griffin BT, Kharoshankaya L, Cryan JF, Boylan GB. Pharmacotherapy for neonatal seizures: current knowledge and future perspectives. Drugs. 2016;76:647-61.

2. Sankaraneni R, Lachhwani D. Antiepileptic drugs a review. Pediatr Ann. 2015;44:e36-42

3. Pellock JM, Arzimanoglou A, D'Cruz O, et al. Extrapolating evidence of antiepileptic drug efficacy in adults to children $\geq 2$ years of age with focal seizures: the case for disease similarity. Epilepsia. 2017:58:1686-96.

4. Yozawitz E, Stacey A, Pressler RM. Pharmacotherapy for seizures in neonates with hypoxic ischemic encephalopathy. Paediatr Drugs. 2017; 19:553-67.

5. Linder $\mathrm{C}$, Wide $\mathrm{K}$, Walander $\mathrm{M}$, et al. Comparison between dried blood spot and plasma sampling for therapeutic drug monitoring of antiepileptic drugs in children with epilepsy: a step towards home sampling. Clin Biochem. 2017;50:418-24.

6. Landmark CJ, Johannessen SI, Tomson T. Dosing strategies for antiepileptic drugs: from a standard dose for all to individualised treatment by implementation of therapeutic drug monitoring. Epileptic Disord. 2016; 18:367-83.

7. Fisher RS, Acevedo C, Arzimanoglou A, et al. ILAE official report: a practical clinical definition of epilepsy. Epilepsia. 2014:55:475-82.

8. Scheffer IE, Berkovic S, Capovilla G, et al. ILAE classification of the epilepsies: position paper of the ILAE commission for classification and terminology. Epilepsia. 2017:58:512-21.

9. Shellhaas RA, Wusthoff CJ, Tsuchida TN, et al. Profile of neonatal epilepsies: characteristics of a prospective US cohort. Neurology. 2017 89:893-9.

10. Sands TT, Balestri M, Bellini G, et al. Rapid and safe response to low-dose carbamazepine in neonatal epilepsy. Epilepsia. 2016;57:2019-30.

11. Yamamoto $\mathrm{H}$, Okumura A, Fukuda M. Epilepsies and epileptic syndromes starting in the neonatal period. Brain Dev. 2011;33:213-20.

12. Go CY, Mackay MT, Weiss SK, et al. Evidence-based guideline update: medical treatment of infantile spasms. Report of the guideline development subcommittee of the American academy of neurology and the practice committee of the child neurology society. Neurology. 2012; 78:1974-80

13. Hancock EC, Osborne JP, Edwards SW. Treatment of Infantile Spasms Copyright (C) 2014 the Cochrane Collaboration. Hoboken: Publicado Por John Wiley and Sons, Ltd.; 2014.

14. Tournay AE. DynaMed Plus: patients with Lennox-Gastaut Síndrome. Spain: Marzo; 2018

15. Epilepsies: Diagnosis and Management. Clinical Guideline Publicada: 11 Enero; 2012. http://www.nice.org.uk/guidance/cg137.

16. Lemmon ME, Kossoff EH. New treatment options for lennox-gastaut syndrome. Curr Treat Options Neurol. 2013;15:519-28.

17. Hancock EC, Cross H. Treatment of Lennox-Gastaut syndrome. Copyright (C) 2013 the Cochrane Collaboration. Hoboken: Publicado Por John Wiley and Sons, Ltd.; 2013.

18. Motte J, Trevathan E, Arvidsson JF, et al. Lamotrigine for generalized seizures associated with the lennox-gastaut syndrome. Lamictal lennox-gastaut study group. N Engl J Med. 1997:337:1807-12.

19. Kossoff EH, Shields WD. Nonpharmacologic care for patients with lennox-gastaut syndrome: ketogenic diets and vagus nerve stimulation. Epilepsia. 2014;55 Suppl 4:29-33.

20. Lancman $\mathrm{G}$, Virk $\mathrm{M}$, Shao $\mathrm{H}$, et al. Vagus nerve stimulation vs. Corpus callosotomy in the treatment of lennox-gastaut syndrome: a meta-analysis. Seizure. 2013;22:3-8.

21. Thiele EA, Marsh ED, French JA, et al. Cannabidiol in patients with seizures associated with lennox-gastaut syndrome (GWPCARE4): a randomised, double-blind, placebo-controlled phase 3 trial. Lancet. 2018; 391:1085-96.

22. Tzadok M, Uliel-Siboni S, Linder I, et al. CBD-enriched medical cannabis for intractable pediatric epilepsy: the current israeli experience. Seizure. 2016;35:41-4.

23. Kilaru S, Bergqvist AG. Current treatment of myoclonic astatic epilepsy: clinical experience at the children's hospital of Philadelphia. Epilepsia. 2007;48:1703-7.

24. Kelley SA, Kossoff EH. Doose syndrome (myoclonic-astatic epilepsy): 40 years of progress. Dev Med Child Neurol. 2010;52:988-93.

25. von Stülpnagel C, Coppola G, Striano P, et al. First long-term experience with the orphan drug rufinamide in children with myoclonic-astatic epilepsy (Doose syndrome). Eur J Paediatr Neurol. 2012;16:459-63.

26. Mizrahi EM, Watanabe K. Symptomatic neonatal seizures. In: Roger J, Bureau M, Dravet CH, editors Epileptic Syndromes in Infancy, Childhood and Adolescencie. $3^{\text {rd }}$ ed. London: John Libbey; 2002.
27. Weir E, Gibbs J, Appleton R. Panayiotopoulos syndrome and benign partial epilepsy with centro-temporal spikes: a comparative incidence study. Seizure. 2018;57:66-9.

28. Glauser T, Ben-Menachem $\mathrm{E}$, Bourgeois $\mathrm{B}$, et al. ILAE treatment guidelines: evidence-based analysis of antiepileptic drug efficacy and effectiveness as initial monotherapy for epileptic seizures and syndromes. Epilepsia. 2006; 47:1094-120.

29. Glauser T, Ben-Menachem E, Bourgeois B, et al. Updated ILAE evidence review of antiepileptic drug efficacy and effectiveness as initial monotherapy for epileptic seizures and syndromes. Epilepsia. 2013;54:551-63.

30. Wilmshurst JM, Gaillard WD Vinayan KP et al. Summary of recommendations for the management of infantile seizures: task force report for the ILAE commission of pediatrics. Epilepsia. 2015;56:1185-97.

31. Arya R, Giridharan N, Anand V, Garg SK. Clobazam monotherapy for focal or generalized seizures. Cochrane Database Syst Rev. 2018; 7:CD009258.

32. Nevitt SJ, Marson AG, Weston J, Smith CT. Carbamazepine versus phenytoin monotherapy for epilepsy: an individual participant data review. Cochrane Database Syst Rev. 2017;2:CD001911.

33. Nevitt SJ, Smith CT, Weston J, Marson AG. Lamotrigine versus carbamazepine monotherapy for epilepsy: an individual participant data review. Cochrane Database Syst Rev. 2018;6:CD001031.

34. Aneja S, Sharma S. Newer anti-epileptic drugs. Indian Pediatr. 2013; 50:1033-40.

35. Sánchez-Álvarez JC, Ramos-Lizana J, Machado-Casas IS, et al. Combined treatment with antiepileptic drugs. Andalusian epilepsy guide 2015. Rev Neurol. 2015;60:365-79.

36. Marson AG, Al-Kharusi AM, Alwaidh M, et al. The SANAD study of effectiveness of carbamazepine, gabapentin, lamotrigine, oxcarbazepine, or topiramate for treatment of partial epilepsy: an unblinded randomised controlled trial. Lancet. 2007;369:1000-15.

37. Smith CT, Marson AG, Chadwick DW, Williamson PR. Multiple treatment comparisons in epilepsy monotherapy trials. Trials. 2007;8:34.

38. Brodie MJ, Perucca E, Ryvlin P, et al. Comparison of levetiracetam and controlled-release carbamazepine in newly diagnosed epilepsy. Neurology. 2007;68:402-8.

39. Wechsler RT, Li G, French J, et al. Conversion to lacosamide monotherapy in the treatment of focal epilepsy: results from a historical-controlled, multicenter, double-blind study. Epilepsia. 2014;55:1088-98.

40. Lang N, Lange M, Schmitt FC, et al. Intravenous lacosamide in clinical practice-results from an independent registry. Seizure. 2016;39:5-9.

41. Maguire M, Marson AG, Ramaratnam S. Epilepsy (partial). BMJ Clin Evid. $2011 ; 2011: 1214$

42. Smith CT, Marson AG, Williamson PR. Carbamazepine versus phenobarbitone monotherapy for epilepsy. Cochrane Database Syst Rev. 2003; 1:CD001904.

43. Nolan SJ, Smith CT, Pulman J, Marson AG. Phenobarbitone versus phenytoin monotherapy for partial onset seizures and generalised onset tonic-clonic seizures. Cochrane Database Syst Rev. 2013;1:CD002217.

44. Nolan SJ, Marson AG, Pulman J, Smith CT. Phenytoin versus valproate monotherapy for partial onset seizures and generalised onset tonic-clonic seizures. Cochrane Database Syst Rev. 2013;8:CD001769.

45. Privitera MD, Brodie MJ, Mattson $\mathrm{RH}$, et al. Topiramate, carbamazepine and valproate monotherapy: double-blind comparison in newly diagnosed epilepsy. Acta Neurol Scand. 2003;107:165-75.

46. Gamble CL, Williamson PR, Marson AG. Lamotrigine versus carbamazepine monotherapy for epilepsy. Cochrane Database Syst Rev. 2006; 1:CD001031.

47. Arya R, Glauser TA. Pharmacotherapy of focal epilepsy in children: a systematic review of approved agents. CNS Drugs. 2013;27:273-86.

48. Koch MW, Polman SK. Oxcarbazepine versus carbamazepine monotherapy for partial onset seizures. Cochrane Database Syst Rev. 2009; 4:CD006453.

49. Perry S, Holt P, Benatar M. Levetiracetam versus carbamazepine monotherapy for partial epilepsy in children less than 16 years of age. J Child Neurol. 2008;23:515-9.

50. Clobazam has equivalent efficacy to carbamazepine and phenytoin as monotherapy for childhood epilepsy. Canadian study group for childhood epilepsy. Epilepsia. 1998;39:952-9.

51. Bawden HN, Camfield CS, Camfield PR, et al. The cognitive and behavioural effects of clobazam and standard monotherapy are comparable. Canadian study group for childhood epilepsy. Epilepsy Res. 1999; 33:133-43.

52. Rosenow F, Schade-Brittinger $\mathrm{C}$, Burchardi $\mathrm{N}$, et al. The laLiMo trial: lamotrigine compared with levetiracetam in the initial 26 weeks of monotherapy for focal and generalised epilepsy an open-label, prospective, randomised controlled multicenter study. J Neurol Neurosurg Psychiatry. 2012;83:1093-8. 